DOI: 10.12731/2218-7405-2018-11-190-207 УДК 378.016:81

\title{
МОТИВАЦИЯ К ИЗУЧЕНИЮ ИНОСТРАННОГО ЯЗЫКА МАГИСТРАНТОВ ИНЖЕНЕРНЫХ СПЕЦИАЛЬНОСТЕЙ
}

\author{
Финогенова О.Н., Денисенко Ф.Н.
}

В статье представлено исследование мотивов к изучению иностранного языка студентов, обучающихся в магистратуре по инженерным специальностям на межинститутской базовой кафедре «Прикладная физика и космические технологии» Сибирского федерального университета. В результате выявлено преобладание мотивачии магистрантов на свободную речевую коммуникацию. Кроме того, в числе ведущих мотивов выявлены: профессиональные, личностного роста, прикладные (решение конкретных практических задач). На основании выявленных типов мотивов разработаны рекомендации о формах обучения для магистрантов с разными типами учебных мотивов.

Ключевые слова: мотивация; мотивация к изучению иностранного языка; учебная мотиващия; обучение магистрантов; методика обучения иностранному языку; коммуникативный подход; коммуникативный метод.

\section{MOTIVATION OF MASTER'S DEGREE STUDENTS OF ENGINEERING PROGRAMME TO LEARNING FOREIGN LANGUAGES}

\section{Finogenova O.N., Denisenko F.N.}

The article presents a research of motives for learning foreign languages of students studying at the magistracy of engineering programme at the interschool department "Applied physics and space technologies". As a result, the predominance of motivation for fluent speech communi- 
cation is revealed. In addition, professional, personality growth, applied motives (resolving specific practical tasks) are revealed as leading ones. On the base of revealed types of motives the authors worked out some recommendations on teaching forms for masters with different types of motives.

Keywords: motivation; motivation to learning foreign languages; educational motivation; teaching of master's degree students; methods of learning foreign languages; communicative approach; communicative method.

Процессы глобализации охватывают все новые и новые сферы современной жизни. Самоактуализация и развитие личности в современном мире невозможны без владения иностранным языком. Знание иностранного языка необходимо для понимания иностранных текстов, общения с иноязычными коллегами, работы с оборудованием, информационными системами.

Любое международное сотрудничество требует высокой иноязычной подготовки. В этой ситуации иностранный язык рассматривается как обязательный компонент профессиональной подготовки студента и важная предпосылка построения успешной карьеры выпускника в будущем. Само время диктует для современного специалиста любой неязыковой специальности необходимость владения иностранным языком. В федеральном государственном образовательном стандарте высшего образования в перечне общепрофессиональных компетенций инженера определена необходимость «владения, по крайней мере, одним из иностранных языков на уровне социального и профессионального общения, способности применять специальную лексику и профессиональную терминологию языка (ОПК-4)» [1]. Требования стандарта предполагают, что современный специалист должен не только уметь понимать письменную и устную речь, а также писать и говорить, но и уметь эффективно действовать в условиях иноязычного общения, что подразумевает значительно более высокий (по сравнению с актуальным) уровень языковой, речевой и внеязыковой подготовки [2]. 
Знания иностранного языка важны в качестве общекультурных, общепрофессиональных и узкопрофессиональных компетенций. Невзирая на всю значимость владения иностранным языком, магистранты Сибирского федерального университета владеют им далеко не в достаточной степени. Кроме того, уровень их усилий по овладению иностранным языком не удовлетворяет требованиям педагогов. Используя академическую терминологию, сформулируем проблему данной работы как низкий уровень мотивации студентов магистрантов к изучению иностранного языка.. Процесс овладения иностранным языком в искусственных условиях аудиторного освоения имеет ряд особенностей и трудностей. Неодинаковое отношение учащихся к учебной деятельности обусловливается тем, что учение имеет для них различный «личностный смысл» [3]. В каждом конкретном случае учащихся побуждают к учению те или иные мотивы или система мотивов, разных по своей значимости [4].

Проблема недостаточности уровня успеваемости студентов является основанием для определения объекта исследования - мотивов овладения иностранным языком магистрантов-инженеров.

В перечне трудностей, препятствующих изучению иностранного языка магистрантами межинститутской базовой кафедры «Прикладная физика и космические технологии» Сибирского федерального университета, на первых позициях находится проблема мотивации. Не все студенты знают, зачем им нужно изучать иностранный язык. Программа обучения не включает мотивирующего блока. Изучаемый материал и осваиваемые компетенции не всегда совпадают с ожиданиями и практическими компетенциями, востребованными учащимися. Поэтому мы считаем необходимым организацию курса иностранного языка, основанную на исследовании запросов студентов. Мы изучили те умения и сферы практического приложения иностранного языка, которые студенты считают важными и нужными для себя.

В будущем магистранты - профессиональные инженеры. С одной стороны, они мотивированы на обучение, имеют сформированные представления о своем профессиональном будущем, сформированные запросы к обучению. С другой стороны, иностранный язык не 
входит в пул профессиональных дисциплин и поэтому мотивация к его изучению у магистров-инженеров не вполне сформирована.

Между тем, процесс обучения магистрантов с очевидностью должен строиться с учетом их запросов, потребностей. Поэтому целью исследования, описанного далее, является выявление «заказа», запросов обучающихся к иностранному языку.

Изучение данной проблемы и поиски возможных способов ее решения нашли отражение в исследованиях многих ученых.

Само понятие мотива является очень широким. Г.А. Швалова представила девять видов мотивов учебной деятельности:

1. Социальные мотивы (долг, ответственность, понимание значимости обучения для всего общества).

2. Познавательные мотивы (стремление больше знать по всем предметам, стать эрудированным).

3. Профессионально-ценностные мотивы (без знаний не будет профессии).

4. Эстетические мотивы (от обучения получаешь удовольствие, раскрываешь свои скрытые способности и таланты).

5. Коммуникативные мотивы (возможность расширять свой круг общения благодаря повышению своего интеллектуального уровня и новым знакомствам).

6. Статусно-позиционные мотивы (стремление через учение или общественную деятельность утвердиться в обществе, в своём вузе, группе и т. д.).

7. Традиционно-исторические мотивы (установленные стереотипы, которые возникли в обществе и укрепились с течением времени).

8. Утилитарно-практические мотивы (необходимость в получении свидетельства об образовании, которое позволяет получить заветное рабочее место).

9. Учебно-познавательные мотивы (стремление усвоить отдельный интересующий предмет и научиться самообразованию) [5].

По данным исследований Хамедовой Г.А., которая изучала мотивацию к изучению иностранного языка студентов электроэнер- 
гетического факультета и факультета информационных технологий Оренбургского Государственного Университета, у студентов с каждым курсом внешние мотивы, такие как «получить диплом о высшем образовании» все более преобладают над внутренними мотивами, такими как «использовать полученные знания в будущей работе» и «в нужной ситуации воспользоваться полученными знаниями» [6].

Однако, как показывает анализ работ, их авторы, исследующие мотивы студентов разных неязыковых образовательных учреждений к изучению иностранного языка, отмечают, что мотивационная сфера студентов получается довольно «размытой» [7].

Шваловой Г.В. был проведён социальный опрос по вопросу мотивации среди студентов Томского политехнического университета. Целями изучения иностранного языка, по мнению студентов, являются следующие: для использования в профессиональной деятельности (52\%), для общения с людьми разных национальностей (22,5\%), для общекультурной подготовки (25,5\%). Мотивы изучения иностранного языка студенты хорошо осознают, достаточно высоко оценивают каждый из предложенных вариантов, но делают выбор в пользу мотивов, связанных с профессиональной деятельностью (79,6\%). В оценке своей позиции в процессе изучения иностранного языка мнения студентов разделились: очень нравится изучение иностранного языка - 33,3\%, изучают с большим удовольствием $31,4 \%$, но в том числе $35,3 \%$ студентов высказали свою неудовлетворенность в овладении иностранным языком [5].

Мелёхина Е.А. и Онал И.О., исследуя мотивацию студентов медицинского и технического университетов пришли к выводу, что доминирующими мотивами к учебе в вузе у студентов медицинского и технологического университетов являются мотивы: сделать карьеру, познавательный и престижно-утилитарный, первый из которых можно охарактеризовать как широкий социальный (внешний), а последний - узколичный (внешний). Стремление «получить глубокие и прочные знания» связано с содержанием учебной деятельности, а, следовательно, считается внутренним мотивом. То есть у опрошенных студентов наблюдается преобладание внешней или внешнеор- 
ганизованной мотивации к учению в целом. При этом наблюдалось относительное единодушие в ответах студентов обоих университетов. Исследование направленности мотивации к изучению иностранного языка в целом подтвердило предположение о невысоком уровне развития внутренних (т.е. связанных с самой учебной деятельностью) мотивов у студентов данных вузов [4].

Кушнарева Т.И., рассматривая мотивацию к изучению иностранного языка студентов Академии биоресурсов и природопользования ФГАОУ ВО «Крымский федеральный университет им. В.И. Вернадского» (г. Симферополь), выяснила, что среди мотивов преобладают, в основном, социальные, коммуникативные и познавательные. Студенты считают, что хорошее знание английского языка поможет им при работе на персональном компьютере (75\%) и обеспечит конкурентоспособность при устройстве на работу (73\%); облегчит возможность и условия поездки за границу (66\%); будет способствовать совершенствованию общих и специальных знаний (49\%); поможет понять тексты песен (43\%); получить новые знания (39\%); развить память и мышление (33\%); принимать участие в международных конференциях (21\%); общаться с носителями языка (29\%) и вести с ними деловую и личную переписку (24\%); позволит соответствовать требованиям важных людей (21\%) и не отставать от сверстников (16\%) [8].

$\mathrm{C}$ целью изучения специфики мотивов изучения иностранного языка магистрантами Сибирского Федерального Университета было проведено эмпирическое исследование. В исследовании приняли участие 32 студента магистратуры межинститутской базовой кафедры «Прикладная физика и космические технологии» Сибирского федерального университета, обучающихся по специальностям: «Информационные системы космических аппаратов и центров управления полетами», «Основы проектирования космических аппаратов, «Навигация и управление движением космических аппаратов», «Технология космических аппаратов». Респондентам был предложен опросник (приложение А.) о прикладной пользе иностранного языка, содержащий три задания. В первом они должны были ответить на вопрос, какие возможности представляет для них совершенное 
знание иностранного языка. Каждый из них предложил около шести вариантов ответа в порядке их значимости.

Таблица 1.

Распределение ответов на вопрос «Если я буду в совершенстве знать ИЯ, то я смогу...»

\begin{tabular}{|l|c|}
\hline Общаться с носителями языка & 7 \\
\hline Читать научную литературу & 6 \\
\hline Жить за границей & 4 \\
\hline Смогу узнавать новости & 3 \\
\hline Путешествовать & 3 \\
\hline Повысить самооценку & 2 \\
\hline Писать статьи на иностранном языке & 2 \\
\hline Читать художественную литературу & 2 \\
\hline Работать за границей & 1 \\
\hline Смотреть кинофильмы на иностранном языке & 1 \\
\hline Развивать свои способности & 1 \\
\hline Взаимодействовать с иностранными коллегами & 1 \\
\hline Понимать инструкции к оборудованию & 1 \\
\hline Понимать иностранную речь & 3 \\
\hline
\end{tabular}

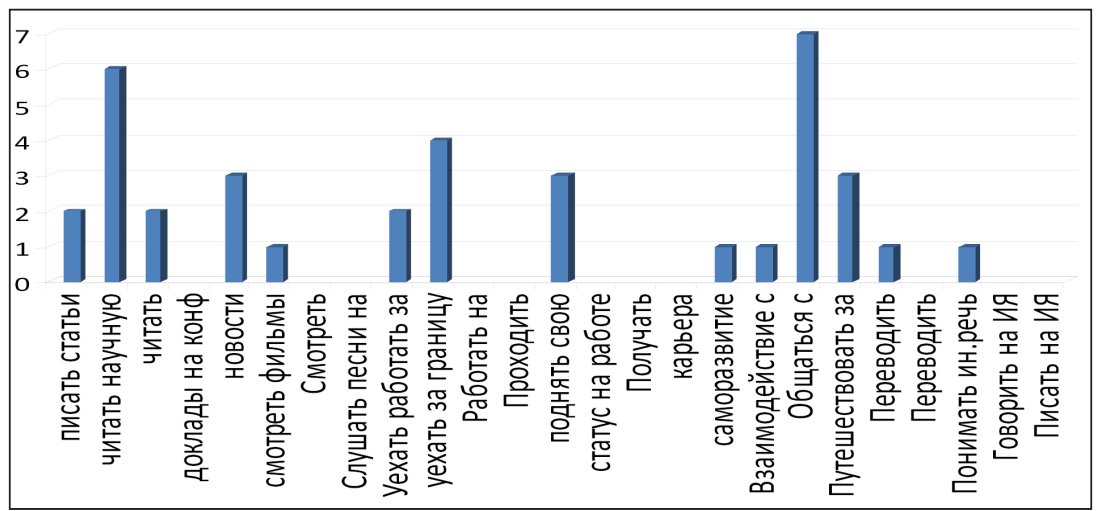

Рис. 1. Распределение ответов магистрантов на вопрос «Если я буду в совершенстве знать ИЯ, то я смогу...»

Из представленных на рисунке 1 и в таблице 1 данных можно видеть, что наиболее важная возможность, возникающая из знания иностранного языка для этой группы студентов - это общение с носителями иностранного языка. На втором месте - способность 
читать научную литературу, на третьем - уехать за границу на постоянное место жительства, на четвертом - поднять самооценку, читать новости зарубежных стран и возможность путешествовать.

Во втором задании респонденты должны были расставить рейтинги значимости задач обучения иностранному языку. Магистранты на первое место по значимости целей обучения иностранному языку поставили понимание иностранной речи, на второе - способность говорить на иностранном языке, на третье - освоение грамматики (Таблица 2).

Таблицуа 2.

Распределение по рангам ответов на вопрос «Преподаватель английского предложил строить курс с учетом ваших задач. Какие задачи вы поставили бы на первое место?»

\begin{tabular}{|l|c|c|c|c|c|c|}
\hline Задачи / ранги & 1 & $\mathbf{2}$ & 3 & 4 & $\mathbf{5}$ & 10 \\
\hline 1. Освоить грамматику ИЯ & 11 & 6 & 6 & 6 & 3 & \\
\hline 2. Научиться понимать иностранную речь & 15 & 7 & 5 & 3 & 1 & \\
\hline 3. Читать литературу на ИЯ & 3 & 9 & 10 & 7 & 3 & \\
\hline 4. Говорить на ИЯ & 12 & 7 & 5 & 7 & 1 & \\
\hline 5. Писать статьи на ИЯ & & 2 & 4 & 4 & 20 & 2 \\
\hline
\end{tabular}

В третьем задании магистранты должны были сочинить рекламный слоган для центра по обучению иностранному языку. Распределение ценностей обучения, выявленное методом контент-анализа, представлено в таблице 3.

Таблицуа 3.

Распределение ответов магистантов по содержанию слоганов, предлагающих обучение иностранному языку

\begin{tabular}{|l|r|}
\hline общение & 12 \\
\hline путешествия & 11 \\
\hline познание & 5 \\
\hline карьера & 4 \\
\hline развитие & 3 \\
\hline работа за границей & 2 \\
\hline деньги & 2 \\
\hline проживание за рубежом & 1 \\
\hline покупки & 1 \\
\hline инструмент & 1 \\
\hline патриотизм & 1 \\
\hline
\end{tabular}


Первое место поделили слоганы, в которых изучение иностранного языка связывалось с возможностями общения («Понимаем весь мир!») и возможности путешествий по всему миру («Теперь ты не будешь тем самым глупым другом. Изучай иностранный язык и путешествуй за границей!»).

На втором месте - познание и возможность карьерного роста («Время не ждет - инвестируй в себя!»).

Таким образом, большинство студентов главным преимуществом знания иностранного языка считают возможность общения с носителями языка. Этим объясняется то, что на первом месте по значимости задач обучения они ставят понимание иностранной речи и способность говорить на иностранном языке (коммуникативный мотив). Возможность общения с носителями языка, в свою очередь, дает возможность путешествий по всему миру, избегая языковых проблем, что, на их взгляд, является еще одной первостепенной ценностью обучения иностранному языку (результат контент-анализа).

Использование знания иностранного языка в профессиональных целях (способность читать научную литературу) студенты ставят на второе место, на третьем появляется возможность уехать за границу на постоянное место жительства, и далее - четвертое и пятое места - занимают познание (саморазвитие), рост самооценки и возможность карьерного роста.

Сравним мотивацию к изучению иностранных языков наших магистрантов и студентов Томского политехнического университета (исследования Г.В. Шваловой). У инженеров Томского университета на первом месте профессиональные интересы, на втором - общение с людьми разных национальностей, на третьем - общекультурная подготовка. В отличие от студентов бакалавриата, у наших магистрантов профессиональный интерес (чтение научной литературы в подлинниках) стоит на втором месте, на первом у них - общение и далее - познание и саморазвитие. Такое различие можно объяснить тем, что магистранты СФУ уже определились с профессией, каждый из них имеет свое рабочее место. Обучаясь в магистратуре, они совершенствуются в выбранной профессиональной области. 
Поэтому их интересуют несколько другие проблемы - возможность расширить свои горизонты - как личные, так и профессиональные за счет общения с людьми других стран и национальностей, узнать условия работы и жизни за рубежом. Отсюда желание свободно понимать и говорить на иностранном языке именно с целью ознакомления с другой культурой. И это направление для них является приоритетным. В профессии же они состоялись, но, тем не менее, на второе место они осознанно ставят профессиональные интересы: занимаясь профессиональной деятельностью, они пришли к выводу, что для участия в международных конференциях и встречах, для чтения и публикации научных статей им не хватает свободного владения иностранным языком.

Нам представляется неоднозначной классификация мотивов, подразделяемых на внешние и внутренние. Сложно охарактеризовать, например, мотив «способность совершать покупки в Интернет-магазинах». К какой категории - внешних или внутренних мотивов его можно отнести? Это, с одной стороны, мотив узкопрактический (внешний), а с другой стороны, действующий в когорте личностных (внутренних) мотивов. Еще более проблематичной является возможность определения типа познавательного мотива, интереса к языку. С одной стороны, это внутренний мотив. С другой стороны, не будучи обеспечен прикладным значением, он может оставаться декларативным, используемым студентом формально и не влияющим реально на его усилия в изучении языка.

На основании результатов эмпирического исследования мы сформировали прикладную типологию мотивов в изучении иностранного языка студентами неязыковых специальностей:

По сфере приложения: профессиональные, коммуникативные, личностного роста и прикладные.

По интенции к использованию: действенные и декларативные, где действенные - те, которые детерминируют поступки, а декларативные используются субъектом без связи с реальным поведением.

Единой модели мотивов изучения иностранного языка студентами неязыковых вузов в настоящее время нет. Анализ мотивов к 
изучению иностранного языка магистрантов межинститутской базовой кафедры «Прикладная физика и космические технологии» Сибирского федерального университета показывает, что в связи со спецификой их профессиональной деятельности и будущих перспектив, на первое место выходит коммуникативный мотив (общение), на второе - профессиональный (чтение научной литературы), на третье - возможность жить и работать за границей и на четвертое - познание (саморазвитие), рост самооценки и возможность карьерного роста.

На основании структуры мотивов магистрантов-инженеров мы сформировали выводы об организации процесса изучения ими иностранного языка. В таблице 4 представлены формы работы со студентами с разными типами мотивов.

Таблицуа 4.

Педагогические средства обучения иностранному языку, соответствующие различным типам мотивации студентов

\begin{tabular}{|c|c|c|c|c|}
\hline $\begin{array}{c}\text { Тип } \\
\text { мотива }\end{array}$ & $\begin{array}{l}\text { Коммуника- } \\
\text { тивные }\end{array}$ & $\begin{array}{c}\text { Профессиональ- } \\
\text { ные }\end{array}$ & $\begin{array}{c}\text { Личностный } \\
\text { рост }\end{array}$ & Прикладные \\
\hline $\begin{array}{l}\text { действен- } \\
\text { ные }\end{array}$ & $\begin{array}{l}\text { Коммуника- } \\
\text { тивный под- } \\
\text { ход } \\
\text { Деловые и } \\
\text { ролевые игры } \\
\text { Дискуссии }\end{array}$ & $\begin{array}{l}\text { Наличие зада- } \\
\text { ний на реальные } \\
\text { профессиональ- } \\
\text { ные действия - } \\
\text { перевод, написа- } \\
\text { ние текстов }\end{array}$ & $\begin{array}{l}\text { Соответствие } \\
\text { заданий инте- } \\
\text { ресам и ценно- } \\
\text { стям студента, } \\
\text { проектные за- } \\
\text { дания }\end{array}$ & $\begin{array}{l}\text { Прикладные за- } \\
\text { дания - купить } \\
\text { авиабилеты на } \\
\text { иноязычном } \\
\text { сайте, заброни- } \\
\text { ровать отель }\end{array}$ \\
\hline $\begin{array}{l}\text { деклара- } \\
\text { тивный }\end{array}$ & $\begin{array}{l}\text { Игровые при- } \\
\text { емы, ролевые } \\
\text { игры }\end{array}$ & $\begin{array}{l}\text { Чтение и пере- } \\
\text { вод профессио- } \\
\text { нальных текстов } \\
\text { для диссертации }\end{array}$ & $\begin{array}{l}\text { Соответствие } \\
\text { заданий инте- } \\
\text { ресам и ценно- } \\
\text { стям студента }\end{array}$ & $\begin{array}{l}\text { Прикладные } \\
\text { задания }\end{array}$ \\
\hline
\end{tabular}

Так, для студентов, основным мотивом которых является коммуникация, наиболее эффективной формой обучения являются коммуникативные технологии обучения, включающие методы активного взаимодействия - дискуссии, игры, драматизации, разыгрывание ситуаций общения, моделирующих наиболее типичные варианты взаимоотношений в реальных условиях. Все это помогает решить проблему возможности общения с носителями языка. В процессе разыгрывания различных коммуникативных ситуаций, 
человек усваивает языковые выражения вместе с ситуацией (гештальтно), т.е. функционально, как осмысленное поведение. Проживая определенную ситуацию, учащийся подсознательно осваивает и систему языка. Кроме того, техника обучения коммуникативной методикой подразумевает создание информационного поля, которое невозможно без доброжелательной атмосферы, т.к. стрессовая ситуация блокирует сознание человека и, соответственно, блокирует овладение языком $[9,10]$. Отбор тематики общения и языкового материала осуществляется исходя из его коммуникативной ценности, соответствия жизненному опыту и интересам студентов. Коммуникативное задание должно предлагать обучающимся проблему или вопрос для обсуждения, причем студенты не просто делятся информацией, но и оценивают ее. Важно, чтобы такое задание делало возможным гибкое использование всех знаний и умений обучающихся. Все задания должны формулироваться так, чтобы в их выполнении был коммуникативный смысл. Для этого необходимо моделировать условия реального общения для создания на занятии атмосферы взаимодействия, что способствует подлинно коммуникативной обстановке.

\section{Технологии обучения студентов}

\section{с профессиональной мотивацией}

Если для студентов, мотивированных на коммуникацию, будет превалировать образовательная деятельность, направленная на формирование умений и навыков устной речи, то для студентов, мотивированных на профессию, соотношение устных и письменных видов речи следует привести в равновесие. Чтение должно стать источником информации для устно-речевого общения и способом обогащения языковых средств обучающихся. Письменная речь также становится подлинно коммуникативным умением: студенты заполняют таблицы, составляют логико-синтаксические схемы, высказывания, пишут эссе, деловые письма, готовят презентации. Коммуникативная методика является возможностью сбалансированного обучения устным (говорение и понимание на слух) и письменным 
(чтение и письмо) формам общения (в рамках общеобразовательных тем профессиональной тематики). В том числе разным формам устно-речевого общения (монологическая, диалогическая и полилогическая речь), а также разным стратегиям чтения (с пониманием основного содержания, с полным пониманием прочитанного, с извлечением нужной или интересующей информации).

Студенты, мотивированные на профессиональный успех, иногда не принимают коммуникативных методов, оценивая их как непродуктивные, не дающие возможность развивать компетенции. Поэтому обучение таких студентов можно строить на основании действий, необходимых для профессионального развития - перевода профессиональных текстов, подготовки презентаций для выступлений на конференциях, подготовки к квалификационным экзаменам типа IELTS, TOEFL. Для таких студентов допустимы индивидуальные формы обучения.

Для студентов, ориентированных на личностный рост, подходят те же типы заданий, что и для «профессионально ориентированных», но с учетом личных интересов. Для них хорошо подойдет работа над проектами.

Студентов, заинтересованных только прикладными проблемами, можно озадачить информационно-поисковой деятельностью (просмотр сайтов интернета) как с целью нахождения материалов профессиональной направленности, так и бытовой (поиск необходимого оборудования, заказ авиа-билетов, бронирование гостиниц для участия в предстоящей конференции.

Для студентов, которые лишь декларируют свои мотивы, подходят те же типы заданий, что и для студентов с «действенными мотивами», но с учетом того, что выполнение этих заданий поможет им получить искомую степень магистра. Для декларирующих профессиональные мотивы это будут задания профессиональной тематики, имеющие отношение к теме его/ее диссертации, для декларирующих коммуникативный мотив - задания (ролевые и деловые игры и тренинги), соответствующие его/ее интересам и ценностям, для декларирующих ориентацию на личностный рост - развивающие 
проектные задания, и прикладные задания интересующих студентов тематик - для студентов, имеющих прикладные мотивы).

Для большинства мотивационных типов эффективно использование коммуникативного подхода, основанного на общении, обмене мнениями, поиске новых решений без готовых ответов и инструкций. И «поскольку студент не получает готовых знаний в форме готовых ответов от преподавателя, то он сам должен предложить свои версии развертывания конкретных ситуаций, и в этих случаях у студента формируются самостоятельность, самоуважение и, самое главное способность самостоятельно думать, рассуждать, анализировать некий динамический процесс возникновения, становления и развития данной ситуации, используя метод «внутренней игры». (О.И. Шушляпин) [11]. По мнению Г.В. Шваловой, коммуникативный подход формирует «...предпосылки коммуникативной мотивации, созданные при постановке соответствующего содержания и соответствующих организационных форм занятия по профессиональному иностранному языку» [5].

\section{Приложение А.}

\section{Опросник}

А. Если я буду в совершенстве знать иностранный язык (ИЯ), то я смогу...

Например: писать статьи на английском языке; читать научную литературу на иностранном языке; читать художественную литературу на иностранном языке, ездить с докладами на международные конференции, слушать новости других стран, смотреть иностранные фильмы, уехать за границу работать, уехать за границу на ПМЖ, поднять свою самооценку, повысить свою оценку (значимость) среди коллег и друзей.

В. Предположим, что преподаватель английского предложил строить курс с учетом ваших задач. Какие задачи вы поставили бы на первое место? В таблице поставьте рейтинги (оценки важности). Напротив самой важной задачи поставьте 1, следующей по важности - два и т.д. 


\begin{tabular}{|l|l|}
\hline 1. Освоил бы грамматику ИЯ & \\
\hline 2. научился бы свободно понимать иностранную речь & \\
\hline 3. научился бы читать литературу на ИЯ & \\
\hline 4. научился бы свободно говорить на ИЯ & \\
\hline 5. научился бы писать статьи на ИЯ & \\
\hline
\end{tabular}

С. Представьте себе, что в Железногорске открывается «Учебный Центр по обучению иностранному языку». Напишите рекламу Центру (2-3 рекламные фразы). В рекламе сделайте акцент на практическую пользу изучения иностранного языка.

\section{Список литературы}

1. Федеральный государственный образовательный стандарт высшего образования. http://fgosvo.ru/fgosvo/151/150/24

2. Милорадов С.А. Некоторые проблемы обучения английскому языку в вузе // Научно-методический электронный журнал «Концепт». 2014. №4 (апрель). С. 91-95. URL: http://e-koncept.ru/2014/14097.htm.

3. Леонтьев А.Н., Проблема деятельности в психологии// Вопросы философии, 1972. № 9. С. 105.

4. Мелёхина Е.А., Онал И.О. Особенности мотивации студентов неязыковых вузов к изучению иностранного языка (на примере медицинского и технического университетов) // Преподаватель высшей школы в XXI веке: Труды. 2007. С. 231-240.

5. Швалова Г.В. Формирование мотивации студентов технического вуза при изучении профессионального иностранного языка // Концепт. 2012. № 11 (ноябрь). URL: http:// www.covenok.ru/koncept/2012/12152.htm

6. Хамедова Г.Н. Исследование мотивации изучения иностранного языка у студентов неязыковых специальностей // Вестник ЧГПУ. 2011, №3. С. 184-192.

7. Онал И.О. К вопросу о мотивации студентов неязыковых вузов к изучению иностранных языков // Сибирский педагогический журнал. Новосибирск: Изд-во ООО «Немо-Пресс». 2007. № 12. С. 131-140.

8. Кушнарева Т.И. Интересно ли студентам неязыкового вуза изучать иностранный язык? // Казанский педагогический журнал. Казань, 2016. № 4 (117). С. 115-118. 
9. Михайлина О.А. Некоторые вопросы коммуникативного подхода в преподавании иностранных языков // Вестник Краснодарского университета МВД России. 2013. №4 (22). С. 131-132.

10. Штыхина К.С. Специфика обучения иностранному языку как средству межкультурного общения студентов неязыковых специальностей // Записки Горного института. 2008. Т. 175. С. 123-124.

11. Шушляпин О.И. Личностно-ориентированный и групповой подход при самостоятельной работе в вузах: обоснование некоторых активных и инновационных методов обучения // Вопросы образования. 2011. № 16. С. 25-30.

\section{References}

1. Federal'nyi gosudarstvennyi obrazovatel'nyi standart vysshego obrazovaniya [Federal state educational standard of higher education]. http:// fgosvo.ru/fgosvo/151/150/24

2. Miloradov S.A. Nekotorye problemy obucheniya angliyskomu yazyku v vuze [Some problems of teaching English at higher educational institution]. Kontsept. 2014. №4 (April). P. 91-95. http://e-koncept.ru/2014/14097. htm.

3. Leont'ev A.N. Problema deyatel'nosty v psihologii [The problem of activity in psychology]. Voprosy filosofii, 1972. № 9. P. 105.

4. Melyohina E.A., Onal I.O. Osobennosti motivatsii studentov neyazykovyh vuzov k izucheniyu inostrannogo yazyka (na primere meditsiskogo i tehnicheskogo universitetov [Particularities of motivation of students of non-linguistic institutions to learning foreign language (in terms of medical and technical universities)]. Prepodavatel'vysshei shkoly $v$ XXI veke: Trudy. 2007, pp. 231-240.

5. Shvalova G.V. Formirovanie motivatsii studentov tehnicheskogo vuza pri izuchenii professional'nogo inostrannogo yazyka [Forming of motivation of technical institution students while learning professional foreign language]. Kontsept. 2012. № 11 (November). http://www.covenok.ru/ koncept/2012/12152.htm.

6. Khamedova G.N. Issledovanie motivatsii izucheniya inostrannogo yazyka u studentov neyazykovyh spezyal'nostei [Research of motivation of 
non-linguistic specialties students to learning foreign language]. Vestnik ChGPU. 2011, №3, pp. 184-192.

7. Onal I.O. $K$ voprosu o motivatsii studentov neyazykovyh vuzov k izucheniyu inostrannyh yazykov [To the issue of motivation of students of non-linguistic institutions to learning foreign languages]. Sibirskiy pedagogicheskiy zhurnal. Novosibirsk: Izdatel'stvo OOO «Nemo-Press». 2007. № 12, pp. 131-140.

8. Kushnareva T.I. Interesno li studentam neyazykovogo vuza izuchat' inostrannyi yazyk? [Are students of non-linguistic institutions interested in learning of foreign language?]. Kazanskiy pedagogicheskiy zhurnal. Kazan’, 2016. № 4 (117), pp. 115-118.

9. Mihailina O.A. Nekotorye voprosy kommunikativnogo podhoda v prepodavanii inostrannyh yazykov [Some issues of communicative approach in teaching foreign languages]. Vestnik Krasnodarskogo universiteta MVD Rossii. 2013. №4 (22), pp. 131-132.

10. Shtyhina K.S. Spetsifika obucheniya inostrannomu yazyku kak sredstvu mezhkul'turnogo obshcheniya studentov neyazykovyh spetsial'nostey [Specific character of teaching English as a means of intercultural communication of non-linguistic specialties students]. Zapiski Gornogo instituta. 2008. V. 175, pp. 123-124.

11. Shushlyapin O.I. Lichnostno-orientirovannyi I gruppovoi podhod pri samostoyatel'noi rabote v vuzah: obosnovanie nekotoryh aktivnyh I innovatsionnyh metodov obucheniya [Personality-centered and group approach to unsupervised working in higher educational institutions: substantiation of some active and innovative methods of teaching]. Voprosy obrazovaniya. 2011. № 16, pp. 25-30.

\section{ДАННЫЕ ОБ АВТОРАХ}

Финогенова Ольга Николаевна, кандидат психологических наук, доцент кафедры общей и социальной педагогики

\section{Сибирский Федеральный Университет}

проспект Свободный, 79, г. Красноярск, 660041, Российская Федераичия

finogenova1971@mail.ru 
Денисенко Фелицата Николаевна, кандидат педагогических наук, доцент межинститутской базовой кафедры «Прикладная физика и космические технологии»

Сибирский Федеральный Университет

ул. Кирова, 12A, г. Железногорск, Красноярский край, 662971, Российская Федерации

\section{DATA ABOUT THE AUTHORS}

Finogenova Olga Nikolaevna, Associate Professor, Department of General and Social Pedagogics

Siberian Federal University

79 Svobodny pr., 660041, Krasnoyarsk, Russian Federation finogenova1971@mail.ru

SPIN-code: 4484-3797

ORCID: 0000-0002-0821-1334

Denisenko Felitsata Nikolaevna, Associate Professor, Interinstitutional base Department "Applied Physics and Space Technology" Siberian Federal University

12A, Kirova str., Zheleznogorsk, 662971, Russian Federation SPIN-code: 9703-8274

ORCID: 0000-0001-8589-6181 